\title{
Educational mobility and weight gain over 13 years in a longitudinal study of young women
}

\author{
Natalie Holowko ${ }^{1 *}$, Mark Jones ${ }^{1}$, Leigh Tooth$^{1}$, Ilona Koupil ${ }^{2}$ and Gita Mishra ${ }^{1}$
}

\begin{abstract}
Background: Limited evidence exists about the role of education and own educational mobility on body weight trajectory. A better understanding of how education influences long term weight gain can help us to design more effective health policies.

Methods: Using random effects models, the association between i) highest education ( $n=10$ 018) and ii) educational mobility over a 9 year period ( $n=9$ 907) and weight gain was analysed using five waves of data (over 13 years) from the Australian Longitudinal Study on Women's Health 1973-78 cohort (from 18-23 years to 31-36 years).

Results: Highest educational attainment was inversely associated with weight at baseline and weight gain over 13 years. Compared to high educated women, those with a low (12 years or less) or intermediate (trade/certificate/ diploma) education, respectively, weighed an additional $2.6 \mathrm{~kg}$ (95\% Cl:1.9 to 3.1) and $2.5 \mathrm{~kg}$ (95\% Cl:1.9 to 3.3) at baseline and gained an additional $3.9 \mathrm{~kg}$ (95\% Cl:2.6 to 5.2) and $3.1 \mathrm{~kg}$ (95\% Cl:2.6 to 3.9) over 13 years. Compared to women who remained with a low education, women with the greatest educational mobility had similar baseline weight to the women who already had a high education at baseline (2.7 kg lighter ( $95 \% \mathrm{Cl}:-3.7$ to -1.8$)$ and $2.7 \mathrm{~kg}$ lighter (95\% Cl:-3.4 to -1.9), respectively) and similarly favourable weight gain (gaining $3.1 \mathrm{~kg}$ less (95\% Cl:-4.0 to -2.21) and $4.2 \mathrm{~kg}$ less (95\% Cl:-4.8 to -3.4 ) over the 13 years, respectively).

Conclusions: While educational attainment by mid-thirties was positively associated with better weight management, women's weight was already different in young adult age, before their highest education was achieved. These findings highlight a potential role of early life factors and personality traits which may influence both education and weight outcomes.
\end{abstract}

Keywords: Educational status, Longitudinal studies, Social inequalities, Weight trajectory, Weight gain

\section{Background}

Overweight and obesity are of high concern due to adverse health risks associated with increased body weight; including cardiovascular disease, hypertension and cancer [1]; excess obstetric risks for both mother and offspring [2]; and the intergenerational transfer of adult metabolic risk through intrauterine growth and prenatal programming of adipose tissue [3]. With a noted steady pattern of weight gain across the life course [4,5], investigating determinants of patterns of long term weight change is of increasing priority.

\footnotetext{
* Correspondence: n.holowko@uq.edu.au

${ }^{1}$ Centre for Longitudinal and Life Course Research, School of Population Health, University of Queensland, Herston Road, 4006 Brisbane, Australia Full list of author information is available at the end of the article
}

Studies in high income countries, including the U.S., Australia, U.K. and Sweden, show an inverse association between adult socioeconomic position (SEP) and body mass index (BMI) across the life course, using education [4-10] and occupation $[4,8,11]$. This trend is found among women in early-mid $[6,7,9,10,12-14]$ and midlate adulthood $[7,8,11]$, while some studies report no association $[15,16]$. Suggested mechanisms include health related behaviours and social/material resources with an established association with weight gain; including physical activity (low levels), high fat/energy intake [8,17]; smoking (quitting) [8]; alcohol consumption (mixed associations, potentially u-shaped) [18]; sitting time (increased levels) [19]; marital status (partnered), higher initial BMI and having children [5].

\section{Ciomed Central}


High mean weight gain over four [15] and 10 year [5] periods is found in women aged 18-23 years, and over five years [20] in women aged 35-44 years; with weight differences by SEP increasing among younger female cohorts $[14,15]$. This trend is significant in itself, let alone increasing maternal BMI being considered a high risk obstetric condition, associated with gestational diabetes mellitus [2] and hypertension [21], as well as offspring obesity in childhood [22].

Previous research using the Australian Longitudinal Study on Women's Health (ALSWH) 1973-78 cohort found that highly educated women in their early twenties had a significantly lower BMI four years later [23]; and that in relation to having children, high educated women (at age 28-33 years) also gained relatively less weight over a 10 year period [5]. Within the U.S. Coronary Artery and Risk Development in Young Adults (CARDIA) study [24], among 18-30 year old women, only education at follow up seven years later was inversely associated with BMI change.

Few studies have explored the effect of when education is measured (early or later adulthood) and changes in education level on body weight trajectory. Such knowledge may assist in better understanding the social patterning of body weight and differing associations found between different studies [15,16,23,24].

This research explores how education may influence long term weight gain in women, by investigating the effect of education measured in early and later adulthood. We focused on detailed investigation of the relationship between i) highest achieved education by mid-thirties and ii) educational mobility (from early-mid twenties to early-mid thirties) with baseline body weight and rate of change over 13 years. We also explored baseline characteristics in women based on their highest achieved education.

\section{Methods \\ Study participants}

The ALSWH began in 1996, using a sample of women randomly selected from the national health insurance database (Medicare), consisting of all Australian citizens and residents, with a deliberate oversampling of rural/ remote women. Detailed information about the three original ALSWH cohorts (41 500 women) can be found elsewhere [25]. The ALSWH study is approved by the Human Research Ethics Committees of the Universities of Newcastle and Queensland. Informed consent was given by all participants of the study.

Our sample was drawn from the cohort born 1973-78; aged 18-23 at baseline and found generally representative of the female population for their age [26].

Of the 14247 women who answered the baseline survey, 9688 (68\%) completed Survey Two (2000; aged
22-27 years); 9081 (64\%) completed Survey Three (2003; aged 25-30 years); 9145 (64\%) completed Survey Four (2006; aged 28-33 years); and 8200 (58\%) completed Survey Five (2009; aged 31-36 years). Relatively high attrition between baseline and Survey Two is thought to result from, among other things, a high level of geographical mobility and changes in surname upon marrying [25].

Our sample was restricted to women with body weight reported in two or more surveys, resulting in 11436 women (see Additional file 1). For our analysis with a main exposure of highest achieved education the sample size was 10018 women, and for educational mobility (from early to mid-twenties up to early to mid-thirties) it was 9907 women.

We additionally ran the analyses for both exposures using data imputed for all women with one body weight ( $\mathrm{n}=13$ 862). We used PROC MI, with 20 imputations using fully conditional specification, to impute all outcomes, exposures, and covariates used in the mixed models. We also included auxiliary variables associated with missingness in the imputation model [27].

\section{Measures}

\section{Outcome - Body weight and weight gain}

At each survey, women were asked "How much do you weight without clothes or shoes (if you are not sure, please estimate)". Women could answer in kilograms/ grams or stones/pounds (these measurements were then converted into kilograms/grams). From Survey Four (2006, aged 28-33 years) onwards, pregnant women were specifically asked to report their weight in the month prior to their pregnancy. Given this, weight for women pregnant at Survey One $(1996, \mathrm{n}=90)$, Two (2000, $\mathrm{n}=78$ ) or Three $(2003, \mathrm{n}=30)$ was excluded from that respective survey.

\section{Exposures - Indicators of socioeconomic position}

Two key SEP indicators were explored: (i) highest achieved education, measured as participants own education at Survey Five (or Survey Four if missing) categorised as: low (high school certificate or lower), intermediate (trade/ apprentice/certificate/diploma) or high (degree/higher degree); and (ii) educational mobility, from Survey Two (carried forward from Survey One if missing) to Survey Five (carried forward from Survey Four if missing) (see Additional file 1). Using education from Survey Two gave the youngest women in the cohort opportunity to have completed a degree. Educational mobility was categorised as: stable low, low-intermediate, stable intermediate, upgrade to high (low-high and intermediate-high) and stable high.

Sensitivity analyses for education level were conducted using i) education at Survey Five only $(n=9$ 037); and ii) 
educational mobility from Survey Two to Five (no carrying forward) as the main exposure $(n=8$ 162) (results available upon request). Sensitivity analyses using all women with one body weight are presented in Additional files 2 and 3.

\section{Covariates \\ Demographic, psychosocial, material, behavioural and reproductive variables}

Due to deliberate initial oversampling of women living in rural and remote areas of Australia, area of residence was adjusted for in all models, categorised as urban (major cities), rural (inner regional), and remote (outer regional/remote). Additionally, all models included age and height centred at the cohort means of 20.8 years and $165.9 \mathrm{~cm}$. The following variables commonly associated with socioeconomic position and body weight were considered for inclusion.

At each survey, questions were asked to determine marital status (married/defacto, separated/divorced/widowed, never married); living arrangement (partner/children; alone; parents/relatives; non-family); number of children (none; one; two; three or more) based on reported dates of birth of children; smoking status (current smoker; nonsmoker; ex-smoker); alcohol intake (never/rarely; risky/ high risk $15+$ drinks/week; low risk $\leq 14$ drinks/week; never/rarely), based on the Australian National Health and Medical Research Council (NHMRC) guidelines [28]; physical activity as $\mathrm{MET} / \mathrm{mins}$ per week (nil/sedentary 0-40; low 40-<600; moderate $600-<1200$; high $\geq 1200$ ) [29]; ability to manage on income (impossible/always difficult; sometimes difficult; not too bad/easy) ; body shape dissatisfaction (not at all; slightly; moderately; markedly); self-rated health (excellent; very good; good; poor/fair); and health transition (better; about the same; worse), comparing health to a year ago.

Mental health (poor $\leq 52$; good $>52$ ) was measured using the Mental Health Index (MHI-5) subscale of the SF-36 (Medical Outcomes Study short form 36 health survey) [30]. Age at birth of first child was based on most recent information. Country of birth was asked at baseline (Australia; other English speaking; Europe (including Turkey, Russia); Asia; other (including the Middle East)).

For descriptive analyses, the World Health Organisation's (WHO) categories for BMI were used; underweight $\left(<18.50 \mathrm{~kg} / \mathrm{m}^{2}\right)$, healthy weight $\left(18.50-24.99 \mathrm{~kg} / \mathrm{m}^{2}\right)$, overweight $\left(25.00-29.99 \mathrm{~kg} / \mathrm{m}^{2}\right)$ and obese $\left(\geq 30.00 \mathrm{~kg} / \mathrm{m}^{2}\right)$ [31].

\section{Statistical analyses}

Cross sectional analyses investigated trends in weight with increasing age, from $18-23$ to 31-36 years. Unweighted statistics are presented, since weighting for area of residence (due to an oversampling of rural women) did not result in significantly different results.
Random effects models (using SAS PROC MIXED) were used to investigate the association of education and educational mobility with weight measured at five time points over 13 years. While mixed models are robust to missing data under the assumption of missing at random (MAR), results from sensitivity analyses using imputed data can be found in Additional files 2 and 3. Each subject had their own intercept and slope (random effects), accounting for correlations between observations within individuals [32]. All other variables were modelled as fixed effects. The time scale used was number of years between baseline (1996) and the return of each survey. A quadratic term for time was included in all models, given a slight attenuation in the increase of weight over time. Results from the random effects Models 1 were used to plot baseline weight and weight gain overtime in the figures presented.

Final selection of covariates was based on $10 \%$ or greater change in primary point estimates, which according to Greenland [33] is more robust than stepwise regression or significance testing approaches. None of the covariates were highly correlated with the SEP exposures, which could have introduced bias in the adjusted models. Covariates were included as categorical or ordinal, fixed or time-varying using model comparison. Model assessment was made comparing Akaike Information Criteria (AIC) goodness of fit statistics, with lower values indicating a better fit. All analyses were completed in SAS version 9.4 for Windows (SAS Institute Inc., Cary, NC).

\section{Results}

A higher percentage of the 2811 women excluded from our final sample had a low education, no children, never/ rarely drink alcohol, had poor mental health and were underweight, born outside of Australia, current smokers and sedentary (see Table 1). These women had a younger mean age at birth of first child.

Mean body weight increased from $62.7 \mathrm{~kg}$ at Survey One to $71.3 \mathrm{~kg}$ at Survey Five. The greatest increases in educational mobility were between baseline and Survey Two; at which point $35 \%$ of women had a low, $26 \%$ had an intermediate and 39\% a high education (results available upon request). In contrast, at Survey Five 18\% of women had a low, $28 \%$ an intermediate and $54 \%$ a high education.

Results from the random effects model show an inverse association between highest achieved education and both baseline weight and weight gain. Compared to women with a high education (see Table 2, model 1) who were lightest at baseline and gained the least per year $(\sim 0.8 \mathrm{~kg})$, women with a lower education were approximately $2.5 \mathrm{~kg}$ heavier at baseline and gained approximately an additional $0.24-0.29 \mathrm{~kg} /$ year.

Weight gain among all education groups has only slightly attenuated over time (see Figure 1). 
Table 1 Baseline characteristics of 1973-78 cohort ALSWH women included/excluded from the sample ${ }^{\dagger}$ $(\mathrm{N}=14$ 247)

\begin{tabular}{ccc}
\hline & Included \\
$\mathrm{N}=11,436^{\dagger}$ & $\begin{array}{c}\text { Excluded } \\
\mathrm{N}=2,811^{\dagger}\end{array}$ & P-value \\
\hline
\end{tabular}

Baseline characteristics

Mean (Std Dev)

Weight $(\mathrm{kg})$

Height $(\mathrm{cm})$

Age at birth of first child**

Percentage (\%)

BMI

Underweight $(<18.5)$

Normal weight (18.5-24.9)

Overweight (25.0 - 29.9)

Obese $(\geq 30.0)$

Education $^{* * *}$

Low

Intermediate

High

Number of children

No children

1

2

$3+$

Marital status

Never married

Married/de facto

Separated/divorced/widowed

Living arrangement

Parents/relatives

Partner/children

Non-family

Alone

Physical activity

Nil/Sedentary

Low

Moderate

High

Alcohol intake

Never/rarely

Low risk

$\begin{array}{lll}62.7(12.5) & 61.8(13.3) & <0.0001 \\ 165.9(7.1) & 165.3(8.2) & <0.0001 \\ 27.1(4.3) & 23.1(3.7) & 0.0089\end{array}$

$<0.0001$

$9.5 \quad 13.6$

$69.0 \quad 64.3$

$15.3 \quad 15.4$

$<0.0001$

$70.7 \quad 74.0$

$17.1 \quad 19.7$

$12.2-6.3$

$<0.0001$

$93.1-97.6$

5.3

1.3

0.3

77.7

21.6

0.7

49.3

26.9

17.7

6.1

6.0

37.1

13.4

43.5

41.8

52.9

$<0.0001$

$<0.0001$
$6.2 \quad 6.7$
Table 1 Baseline characteristics of 1973-78 cohort ALSWH women included/excluded from the sample ${ }^{\dagger}$ ( $N=14$ 247) (Continued)

Risky/high risk

5.3

6.7

Smoking status

$<0.0001$

Non-smoker

$54.1 \quad 44.9$

Ex-Smoker

$15.1 \quad 15.9$

Current smoker

30.8

39.2

Mental health (based on MHI-5)

$<0.0001$

Poor $(\leq 52)$

$20.7 \quad 25.8$

Good (>52)

79.3

74.2

Self-rated health

$<0.0001$

Excellent

Very good

Good

Poor/Fair

Ability to manage on income

$<0.0001$

Easy/Not too bad

Difficult sometimes

Impossible/Always difficult

Body shape dissatisfaction

Not at all

$12.8 \quad 11.4$

39.9

11.4

35.8

33.1

11.5

40.7

$50.1 \quad 41.4$

$32.6 \quad 35.5$

$17.4 \quad 23.1$

$<0.0001$

Slightly

$\begin{array}{ll}8.8 & 12.8\end{array}$

Moderately

$25.9 \quad 23.4$

$31.9 \quad 28.9$

Markedly

Country of birth

$33.3 \quad 34.9$

Australia

Other English speaking

Europe

Asia

Other (incl. Middle East)

Area of residence

Urban (major cities)

Rural (inner regional)

Remote (outer regional/ remote)

$92.6 \quad 86.9$

$3.6 \quad 4.6$

$0.9 \quad 1.6$

$2.0 \quad 5.4$

$0.8 \quad 1.5$

${ }^{\dagger}$ sample sizes change slightly due to missing values for some variables.

*P-values from independent $t$-tests for continuous variables and from Pearson chi square tests for categorical variables.

**Age at birth of first child is based on reported information up to Survey Five. ***Education at baseline (Low - higher school certificate or lower ( $\leq 12$ years), Intermediate - trade/certificate/diploma, High - degree/higher degree).
Education and weight gain over 13 years

The significant association between highest achieved education and both baseline weight and weight gain remained after adjusting for covariates; social differences in weight gain did not change, while differences in baseline weight by education level narrowed slightly (see Table 2, model 2). 
Table 2 Baseline weight and weight gain* over 13 years by highest education ${ }^{\dagger}$ in $1973-78$ cohort ALSWH women $\left(n=9573^{* *}\right)$

\begin{tabular}{|c|c|c|c|}
\hline & $\%$ weighted (unweighted) & Model 1 Estimate $(95 \% \mathrm{CI})$ & Model 2 Estimate $(95 \% \mathrm{Cl})$ \\
\hline Baseline weight (kg) & & $60.51(60.06,60.97)$ & $58.89(58.11,59.68)$ \\
\hline \multicolumn{4}{|c|}{ Difference in baseline weight by highest achieved education ${ }^{\dagger}$} \\
\hline High & $51.3(46.9)$ & Reference & Reference \\
\hline Intermediate & $29.5(31.1)$ & $2.48(1.87,3.08)$ & $1.67(1.08,2.26)$ \\
\hline Low & $19.3(22.0)$ & $2.63(1.93,3.33)$ & $1.70(1.00,2.39)$ \\
\hline Increase per year (kg) & & $0.82(0.77,0.87)$ & $1.18(1.12,1.24)$ \\
\hline \multicolumn{4}{|c|}{ Difference in increase per year by highest achieved education ${ }^{\dagger}$} \\
\hline High & & Reference & Reference \\
\hline Intermediate & & $0.24(0.19,0.28)$ & $0.23(0.19,0.28)$ \\
\hline Low & & $0.29(0.24,0.35)$ & $0.27(0.22,0.33)$ \\
\hline Attenuation per year (time*time) & & $-0.02(-0.26,-0.20)$ & $-0.05(-0.06,-0.05)$ \\
\hline
\end{tabular}

\section{Educational mobility and weight gain over 13 years}

Results from the random effects model show weight at baseline was significantly different for women defined by their educational mobility. Compared to women with a stable low education, who were the heaviest at baseline (see Table 3, model 1), women with a stable high education or who upgraded to a high education (greatest educational mobility) weighed significantly less at baseline $(\sim 2.7 \mathrm{~kg}$ lighter; 1.8 and $2.1 \mathrm{~kg}$ lighter, respectively, when fully adjusted).
Highest achieved education was indicative of weight change, with women who achieved the highest education level by Survey Five gaining slightly less weight per year. Compared to women with a stable low education who gained $1.1 \mathrm{~kg} /$ year ( 1.5 kg/year fully adjusted), women with a stable high education gained $0.3 \mathrm{~kg} /$ year less and women who upgraded to the highest education gained $0.24 \mathrm{~kg} /$ year less $(0.2 \mathrm{~kg} /$ year fully adjusted). There was no significant difference between the women with a stable low and low-intermediate education. Women with

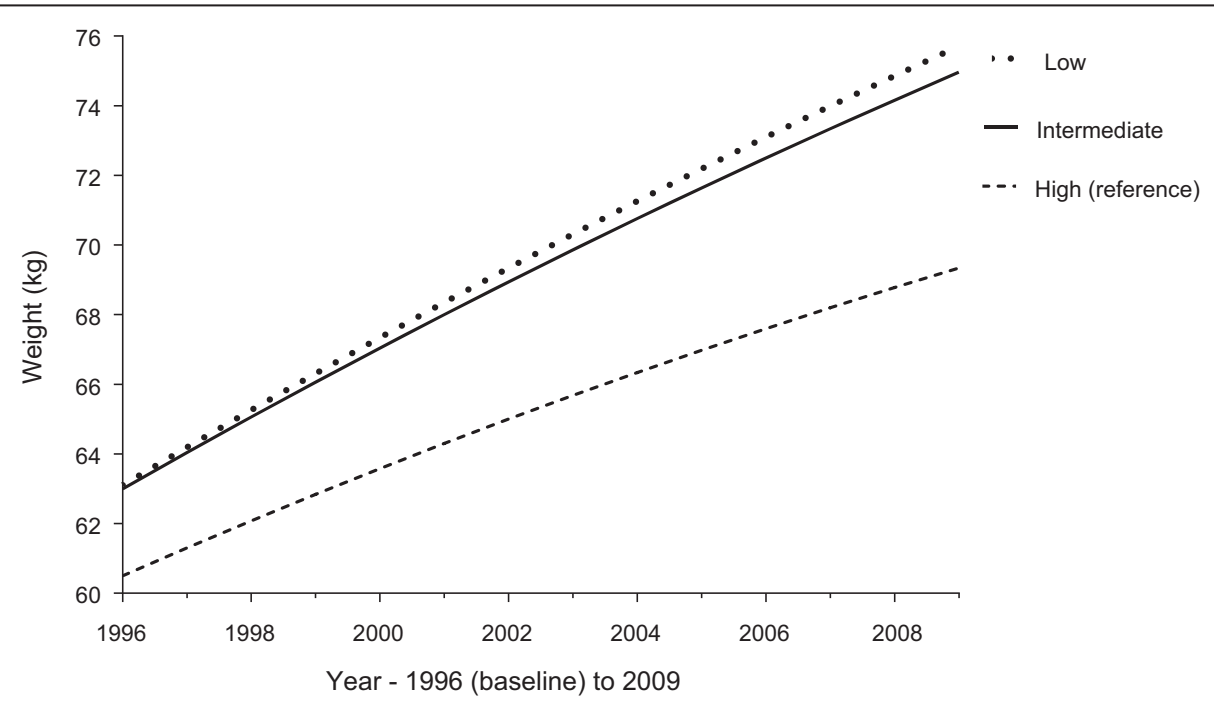

Figure 1 Highest achieved education and weight gain over 13 years in women from the 1973-78 ALSWH cohort ( $n=9573)$. Difference in baseline weight and weight gain over 13 years (random effects model with a random intercept and slope, adjusted for area of residence and baseline centred age and height), based on highest achieved education at Survey Five (age 31-36 years). Education categorised as 'Low' (higher school certificate or lower - $\leq 12$ years), 'Intermediate' (trade/certificate/diploma) or 'High' (degree or higher). 
Table 3 Baseline weight and weight gain ${ }^{*}$ over 13 years by educational mobility ${ }^{\dagger}$ in $1973-78$ cohort ALSWH women (n= $\left.9463^{* *}\right)$

\begin{tabular}{|c|c|c|c|}
\hline & $\begin{array}{l}\% \text { weighted } \\
\text { (unweighted) }\end{array}$ & $\begin{array}{c}\text { Model } 1 \\
\text { estimate }(95 \% \mathrm{Cl}) \\
\end{array}$ & $\begin{array}{c}\text { Model } 2 \\
\text { estimate }(95 \% \mathrm{Cl}) \\
\end{array}$ \\
\hline Baseline weight (kg) & & $63.15(62.46,63.85)$ & $57.85(56.77,58.92)$ \\
\hline \multicolumn{4}{|c|}{ Difference in baseline weight by educational mobility ${ }^{\dagger}$} \\
\hline Stable low & $18.9(21.7)$ & Reference & Reference \\
\hline Low-intermediate & $9.9(10.9)$ & $-0.78(-1.8,0.27)$ & $-0.78(-1.78,0.21)$ \\
\hline Stable intermediate & $19.8(20.5)$ & $0.17(-0.68,1.02)$ & $0.31(-0.51,1.12)$ \\
\hline Upgrade to high & $12.8(12.0)$ & $-2.71(-3.68,-1.75)$ & $-2.13(-3.07,-1.19)$ \\
\hline Stable high & $38.6(34.9)$ & $-2.66(-3.41,-1.91)$ & $-1.77(-2.52,-1.02)$ \\
\hline Increase per year $(\mathbf{k g})$ & & $1.12(1.06,1.18)$ & $1.45(1.39,1.52)$ \\
\hline \multicolumn{4}{|c|}{ Difference in increase per year by educational mobility ${ }^{\dagger}$} \\
\hline Stable low & & Reference & Reference \\
\hline Low-intermediate & & $0.04(-0.09,0.07)$ & $0.01(-0.07,0.08)$ \\
\hline Stable intermediate & & $-0.09(-0.15,-0.22)$ & $-0.07(-0.13,-0.002)$ \\
\hline Upgrade to high & & $-0.24(-0.31,-0.17)$ & $-0.20(-0.27,-0.13)$ \\
\hline Stable high & & $-0.32(-0.37,-0.26)$ & $-0.28(-0.33,-0.22)$ \\
\hline Attenuation per year (time $x$ time) & & $-0.02(-0.03,-0.02)$ & $-0.05(-0.06,-0.05)$ \\
\hline
\end{tabular}

"Random effects models (intercept and slope) with weight measured at age 18-23 years, 22-27 years, 25-30 years, 28-33 years and 31-36 years

${ }^{+}$Change in education level from age 22-27 years to age 31-36 years: (Low - higher school certificate or lower ( $\leq 12$ years), Intermediate - trade/certificate/diploma, High - degree/higher degree). Upgrade to high includes women who had a low (70\%) or intermediate (30\%) education who later upgraded to a high education. **Sample slightly smaller than the 9,907 women who had a value for change in education level, due to missing values for some covariates.

Model 1 - baseline centred age, baseline centred height and area of residence.

Model 2 - Model 1 + physical activity, alcohol intake, mental health, self-rated health, number of children, smoking, age at first birth, living arrangement, marital status, health transition, shape dissatisfaction, income management and country of birth.

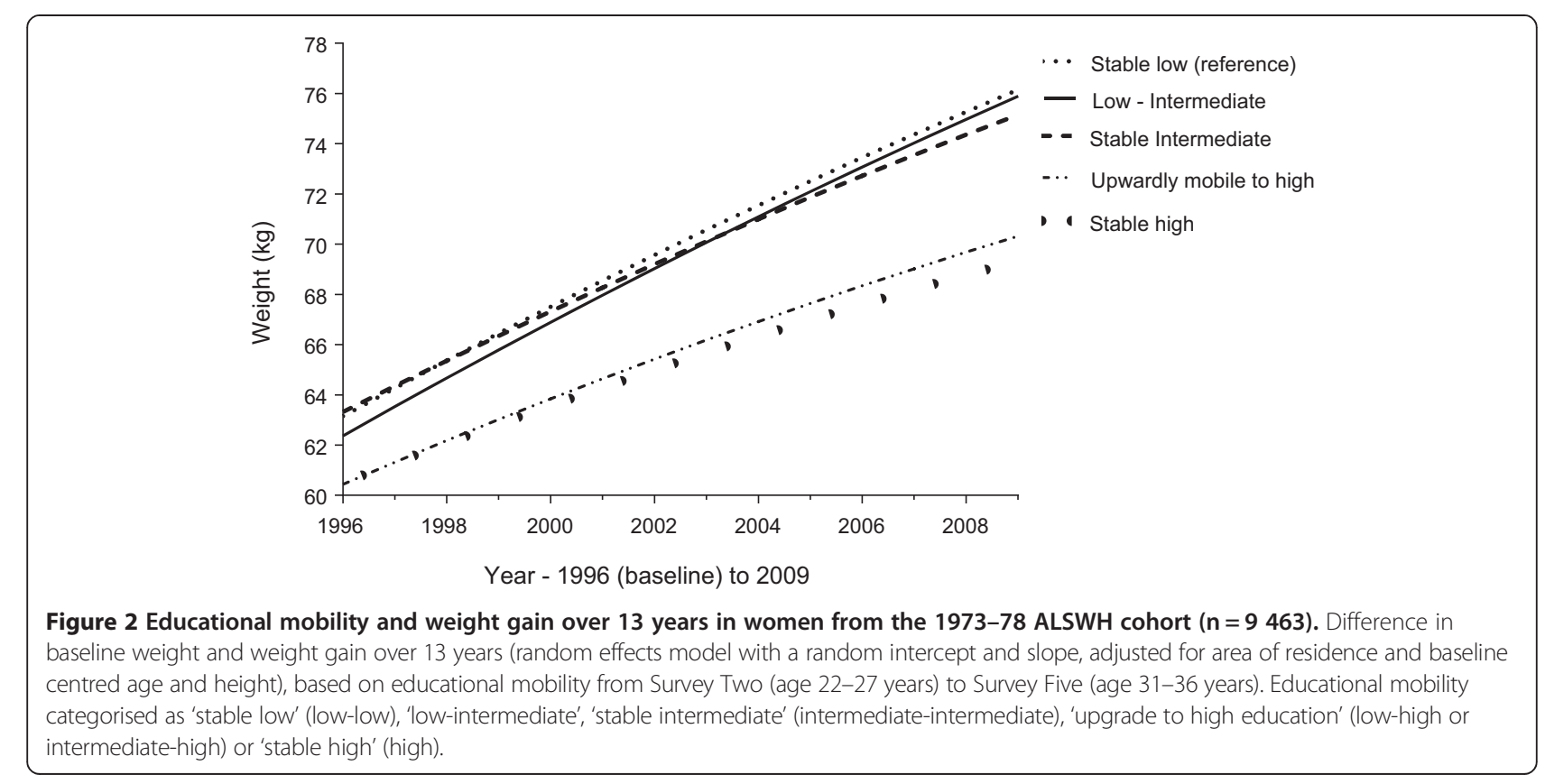


Table 4 Baseline characteristics in 1973-78 cohort ALSWH women based on highest achieved education ${ }^{\dagger}(n=10018)$ Highest achieved education $^{\dagger}$

Low (21\%) $n=2,087^{\ddagger} \quad$ Intermediate (30\%) $n=2,994^{\ddagger} \quad$ High (49\%) $n=4,937^{\ddagger} \quad \mathrm{chi}^{2} / \mathrm{F}$ statistic (P-value)

Baseline characteristics

Mean (Std Dev)

Age (years)

Weight ( $\mathrm{kg}$ )

Height $(\mathrm{cm})$

Age at birth of first child ${ }^{* *}$

Percentage (\%)

BMI

Underweight $(<18.5)$

Normal weight (18.5 -24.9)

Overweight (25.0 - 29.9)

Obese ( $\geq 30.0$ )

20.8 (1.5)

$63.7(13.1)$

$165.4(7.4)$

$25.3(4.3)$

Number of children

No children

1

2

$3+$

Marital status

Never married

Married/de facto

Separated/divorced/widowed

Physical activity

Nil/Sedentary

Low

Moderate

High

Alcohol intake

Never/rarely

Low risk

Risky/high risk

Smoking status

Non-smoker

Ex-Smoker

Current smoker

Mental health (based on MHI-5)

Poor ( $\leq 52)$

Good (>52)

Country of birth

Australia

Other English speaking

$$
\begin{aligned}
& 20.8(1.4) \\
& 63.6(13.3) \\
& 165.7(7.3) \\
& 26.6(4.1)
\end{aligned}
$$

9.2

62.3

18.9

9.6

83.7

12.3

3.3

0.7

62.3

36.0

1.7

8.4

40.1

12.6

38.9

48.8

44.8

6.4

40.9

18.4

40.7

\section{4}

75.6

94.6

3.6

0.3

0.8

42.4

35.2

21.5

78.5

95.0

2.6
$20.7(1.5)$
$61.8(11.1)$
$166.4(6.8)$
$29.1(3.4)$

$9.23(<0.0001)$

$23.6(<0.0001)$

$18.4(<0.0001)$

$529.6(<0.0001)$

* $44.3(<0.0001)$

9.4

73.5

13.3

3.8

$509.9(<0.0001)$

98.2

1.5

0.2

0.02

$704.0(<0.0001)$

88.7

11.1

0.2

$73.5(<0.0001)$

4.4

35.4

13.9

46.3

$121.5(<0.0001)$

36.9

58.7

4.4

$429.7(<0.0001)$

65.2

12.7

22.1

$56.8(<0.0001)$

17.1

82.9
$72.0(<0.0001)$

91.1

4.1 
Table 4 Baseline characteristics in 1973-78 cohort ALSWH women based on highest achieved education ${ }^{\dagger}(\mathrm{n}=10018)$ (Continued)

\begin{tabular}{llll}
\hline Europe & 0.6 & 0.8 & 1.1 \\
Asia & 0.7 & 1.0 & 2.7 \\
Other (incl. Middle East) & 0.5 & 0.6 & 1.0 \\
Area of residence & & & 61.2 \\
Urban (major cities) & 37.3 & 46.6 & 26.5 \\
Rural (inner regional) & 36.5 & 32.4 & 12.3 \\
Remote (outer regional/ remote) & 26.2 & 21.0 & $420.3(<0.0001)$ \\
\hline
\end{tabular}

${ }^{\dagger}$ Achieved at Survey Five (age 31-36 years) (if missing, then from Survey Four) categorised as 'Low' - higher school certificate or lower ( $\leq 12$ years), 'Intermediate' - trade/certificate/diploma or 'High' - degree/higher degree.

${ }^{\ddagger}$ Sample sizes change slightly due to missing values for some variables.

*Mantel-Haenszel chi square used when $>10 \%$ data was missing.

${ }^{* *}$ Age at birth of first child is based on reported information up to Survey Five.

a stable intermediate education gained marginally less per survey compared to women who were stable low. Weight gain among all categories of educational mobility has slightly attenuated over time (see Figure 2).

Sensitivity analyses for both exposures (see Methods) showed similar associations to those presented with marginally lower estimates (results available upon request). Additionally, sensitivity analyses using imputed data showed the same associations to those presented (see Additional files 2 and 3).

\section{Baseline characteristics of women based on their highest achieved education}

While the mean age at baseline was similar for all education groups, women with a high education by Survey Five were significantly lighter and taller at baseline (see Table 4). At baseline, a greater proportion of these women had never had children (98\%); with an older mean age at birth of first child (29.1 years), compared to intermediate (26.6 years) and low (25.3 years) educated women.

Compared to the other two education groups, a significantly smaller proportion of high educated women were separated/divorced/widowed, with the greatest proportion having never married ( $89 \%)$. In contrast to high educated women, at baseline a larger proportion of low educated women were sedentary or had low physical activity levels; never/rarely drank or had risky drinking levels; were current smokers; had poor mental health; were Australian born; and lived in a rural or remote area.

While the above differences at baseline based on highest achieved education were noted, these covariates did not have a large effect on the association between education and body weight, as seen in the fully adjusted models (see Tables $2 \& 3$, model 2).

\section{Discussion}

This study investigated body weight trajectories over 13 years among Australian women aged 18-23 years at baseline. The results suggest that while the mean trend is increasing body weight for all women, adult education level is significantly associated with weight trajectory.

We found that high educated women benefited from gaining less weight over a 13 year period. This is consistent with other studies which have found an inverse association between education and long term weight gain [4-7]. A Finnish study [34], investigating the association between multiple measures of SEP and five year weight gain in midaged women, found that after full adjustment for a range of SEP measures (including parental education, childhood education, childhood and adulthood socioeconomic difficulties, own occupational social class and material resources) only the association between education and weight gain remained; suggesting this might be due to education preceding occupation and income [34]. Given this, one may assume that formal education itself encourages better health and a more promising weight trajectory; possibly through an increased knowledge of health behaviours and greater access to resources. However, assuming that knowledge results in positive behavioural change/practices should be questioned; as shown in a U.S. longitudinal study [6] which found the BMI trajectory of socially advantaged groups to be increasing and indeed higher than socially disadvantaged groups born 10 years earlier, although this could be confounded by timing of measurement.

While women with a high education at Survey Five had the lowest baseline weight and weight trajectory, two interesting findings were apparent regarding educational mobility. Firstly, women who remained with a low education at both time points had a steeper weight trajectory than those who went on to upgrade their education. Secondly, we found that lower educated women with the greatest educational mobility had a similarly favourable baseline weight and trajectory to those who had already achieved this high education earlier on. Our finding support those from a U.S. study of 18-30 year olds which found that, among white women, while education at 
baseline was only associated with BMI at this same time point, education at follow up (7 years after baseline) was associated with both baseline weight and weight at follow up [24]. Our analysis of educational mobility adds to this knowledge by highlighting that, with regards to baseline weight and weight trajectory, little additional advantage is seen in women who obtained this level of education early on compared to later.

This suggests that using education in early adulthood as a fixed marker of SEP may be inaccurate and in fact downplay the association between education and body weight trajectory. It may explain why some studies find an association between education and weight trajectory only among older women [13] or not at all when measuring education at baseline $[15,16]$; while others, find a negative association when using education in later adulthood $[8,20]$.

Additionally, these results suggest that health behaviours/knowledge we might expect in highly educated women may be more related to factors operating earlier in life that lead to obesity, including early developmental patterns [35]. One explanation is that education attainment is influenced by IQ, however the early life environment in which cognitive ability and personality development are nurtured [36] must also be important, not least due to the types of resources available and psychosocial factors that make up that environment, as well as possible early socioeconomic disadvantage. We also tried conditioning for both mother's and father's education, separately and mutually, and found our associations remained the same, with marginally reduced estimates (results not shown). This suggests that even when we take into account early life SEP, there is still an effect of own education. It could be that some shared personality traits exist, which may make an individual more likely to engage in (and successfully obtain) a high education and also more successful at weight management, such as persistence and self-directedness [37].

The main strength of this study is having five waves of data collected over 13 years in a large sample. This gave women adequate time to have completed their education and allowed for a more in-depth analysis into changes in education level than would have been possible with fewer time points. Use of longitudinal methods accommodated for correlation between multiple observations per individual, while allowing for time-varying covariates and changes in behavioural/demographic characteristics which may influence body weight. Additionally, sensitivity analyses showed similar associations to those presented, including analyses using imputed data for both exposures and outcomes.

Potential study limitations should not be overlooked. Consistent with findings in other developed countries, a Melbourne study found an average weight gain of $0.4 \mathrm{~kg} /$ year [20]; while our study found an average gain in mean weight of $0.7 \mathrm{~kg} /$ year ( $8.6 \mathrm{~kg}$ over the follow-up period). While self-reporting includes the possibility of overestimated height and underestimated weight, both are found reasonable to use within epidemiological studies [38]. If weight underreporting is consistent, Baltrus et al. [13] suggest weight trajectory estimates should not be affected; although Brown et al. [5] suggest this may not apply to overweight/obese women, who have a greater tendency for weight underestimation, resulting in estimates biased towards the null. Since education is positively associated with height, we also looked at BMI trajectories and found the same associations as we did with body weight; we chose the latter as it offers a more interpretable result. Given that the significance of weight is dependent on height, we tried to account for this by adjusting all models for height centred at the cohort mean.

An overrepresentation of tertiary educated women in this cohort (12\%, compared to 3\% in the closes Australian census) [26], together with a slightly higher proportion of high educated women included (12\%) than excluded (6\%) from the sample may influence generalizability of results through selection bias.

\section{Conclusion}

Our study highlights the importance of when education is measured, how it is used in analyses and the theoret$\mathrm{ical} /$ causal model that is to be tested; all of which may influence the interpretation of results and the mechanisms through which SEP is thought to influence weight change. Using earlier education to measure the association between SEP and body weight trajectory may result in biased estimates, underestimating the association. High achieved education was significantly associated with a more favourable weight trajectory; with little increased advantage among those who had obtained this high education early on, compared to the women with a lower education who upgraded over the 13 year period. This suggests that behavioural characteristics and health knowledge often associated with a high education may already differentiate women early on; including personality traits related to weight management [37]; early life factors, such as food/flavour preferences [39]; and modelling of parental physical activity and nutritional patterns [40]. Overall, understanding the role of education and the mechanisms through which it may influence body weight may help to identify women, and hence children, at increased risk of an unhealthy weight trajectory.

\section{Additional files}

Additional file 1: Inclusion/exclusion of subjects in our analyses, from women in the ALSWH cohort born 1973-1978. 
Additional file 2: Baseline weight and weight gain ${ }^{*}$ over 13 years by highest education ${ }^{\dagger}$ in 1973-78 cohort ALSWH women, using multiply imputed data $\left(n=13862^{* *}\right)$. "random effects models (intercept only) with weight measured at age 18-23 years, 22-27 years, $25-30$ years, $28-33$ years and $31-36$ years. ${ }^{\dagger}$ education achieved at Survey Five (Low - higher school certificate or lower ( $\leq 12$ years), Intermediate - trade/certificate/diploma, High - degree/higher degree). **women with at least one body weight. Model 1 - Baseline centred age, baseline centred height and area of residence. Model 2- Model $1+$ country of birth, physical activity, alcohol intake, mental health, income management, self-rated health, age at first birth, living arrangements, marital status, shape dissatisfaction.

Additional file 3: Baseline weight and weight gain* over 13 years by educational mobility ${ }^{+}$in $1973-78$ cohort ALSWH women, using multiply imputed data $\left(n=13862^{* *}\right)$. "random effects models (intercept only) with weight measured at age 18-23 years, 22-27 years, 25-30 years, 28-33 years and 31-36 years. ${ }^{\top}$ change in education level from early-mid twenties to early-mid thirties: (Low - higher school certificate or lower ( $\leq 12$ years), Intermediate - trade/certificate/diploma, High - degree/higher degree). Upgrade to high includes women who had a low (70\%) or intermediate (30\%) education who later upgraded to a high education. ${ }^{* *}$ women with at least one body weight. Model 1 - baseline centred age, baseline centred height and area of residence. Model 2 - Model 1 + physical activity, alcohol intake, mental health, self-rated health, number of children, smoking, age at first birth, living arrangement, marital status, health transition, shape dissatisfaction, income management and country of birth.

\section{Competing interests}

The authors declare no competing interests. This work was supported by Australian Commonwealth Department of Health. The Australian Longitudinal Study on Women's Health was conceived and developed by researchers at the University of Newcastle and University of Queensland, Australia. NH is supported by the Australian Postgraduate Award scholarship and GDM is supported by the Australian Research Council Future Fellowship (FT 120100812).

\section{Authors' contributions}

$\mathrm{NH}$ and GM conceived and designed the study. $\mathrm{NH}, \mathrm{MJ}$ and $\mathrm{GM}$ analyzed the data and all authors interpreted the data. NH drafted the article and all authors critically revised the manuscript for important intellectual content and approved the final version for publishing. All authors had full access to the data and take responsibility for the decision to submit for publication.

\section{Acknowledgements}

We would like to thank David Fitzgerald for his assistance with data management for this project. Additionally, we would like to thank all the participants of the Australian Longitudinal Study on Women's Health. NH is supported by the Australian Postgraduate Award scholarship and GDM is supported by the Australian Research Council Future Fellowship (FT 120100812).

\section{Author details}

${ }^{1}$ Centre for Longitudinal and Life Course Research, School of Population Health, University of Queensland, Herston Road, 4006 Brisbane, Australia. ${ }^{2}$ Centre for Health Equity Studies (CHESS), Stockholm University/Karolinska Institute, Sveavägen 160, 10691 Stockholm, Sweden.

\section{Received: 28 May 2014 Accepted: 10 November 2014}

Published: 25 November 2014

\section{References}

1. Novak M, Ahlgren C, Hammarström A: A life-course approach in explaining social inequity in obesity among young adult men and women. Int J Obesity (London) 2006, 30(1):191-200.

2. Gunderson E, Quesenberry C, Lewis C, Tsai A, Sternfeld B, Smith West D, Sidney S: Development of overweight associated with childbearing depends on smoking habit: The Coronary Artery Risk Development in Young Adults (CARDIA) Study. Obes Res 2004, 12(12):2041-2053.

3. Fowden A, Ward J, Forhead A: Control of fetal metabolism: relevance to developmental origins of health and disease. In Developmental Origins of
Health and Disease. Edited by Gluckman P, Hanson M. New York: Cambridge University Press; 2006:130-142.

4. Ball $\mathrm{K}$, Crawford D: Socioeconomic status and weight change in adults: a review. Soc Sci Med 2005, 60(9):1987-2010.

5. Brown W, Hockey R, Dobson A: Effects of having a baby on weight gain. Am J Prev Med 2010, 38(2):163-170.

6. Clarke P, O'Malley P, Johnston L, Schulenberg J: Social disparities in BMI trajectories across adulthood by gender, race/ethnicity and lifetime socio-economic position: 1986-2004. Int J Epidemiol 2009, 38(2):499-509.

7. Sundquist J, Johansson S: The influence of socioeconomic status, ethnicity and lifestyle on body mass index in a longitudinal study. Int J Epidemiol 1998, 27(1):57-63.

8. Lahmann P, Lissner L, Gullberg B, Berglund G: Sociodemographic factors associated with long-term weight gain, current body fatness and central adiposity in Swedish women. Int J Obes Relat Metab Disord 2000, 24(6):685-694.

9. Backholer K, Mannan H, Magliano D, Walls H, Stevenson C, Beauchamp A, Shaw J, Peeters A: Projected socioeconomic disparities in the prevalence of obesity among Australian adults. Aust N Z J Public Health 2012, 36(6):557-563.

10. Flegal $\mathrm{K}$, Harlan W, Landis J: Secular trends in body mass index and skinfold thickness with socioeconomic factors in young adult women. Am J Clin Nutr 1988, 48(3):535-543.

11. Langenberg C, Hardy R, Kuh D, Brunner E, Wadsworth M: Central and total obesity in middle aged men and women in relation to lifetime socioeconomic status: evidence from a national birth cohort. J Epidemiol Community Health 2003, 57(10):816-822.

12. Hardy R, Wadsworth M, Kuh D: The influence of childhood weight and socioeconomic status on change in adult body mass index in a British national birth cohort. Int J Obes Relat Metab Disord 2000, 24(6):725-734.

13. Baltrus P, Everson-Rose S, Lynch J, Raghunathan T, Kaplan G: Socioeconomic position in childhood and adulthood and weight gain over 34 years: The Alameda Study. Ann Epidemiol 2007, 17(8):608-614.

14. Eek F, Östergren P: Factors associated with BMI change over five years in a Swedish adult population. Results from the Scania Public Health Cohort Study. Scand J Public Health 2009, 37(5):534-544.

15. Ball K, Brown W, Crawford D: Who does not gain weight? Prevalence and predictors of weight maintenance in young women. Int I Obes Relat Metab Disord 2002, 26(12):1570-1578.

16. van Lenthe F, Droomers M, Schrijvers C, Mackenbach J: Socio-demographic variables and 6 year change in body mass index: longitudinal results from the GLOBE study. Int J Obes 2000, 24(8):1077-1084.

17. Gearon E, Backholer K, Hodge A, Peeters A: The mediating role of dietary factors and leisure time physical activity on socioeconomic inequalities in body mass index among Australian adults. BMC Public Health 2013, 21(13):1214

18. Wannamethee S, Field A, Colditz G, Rimm E: Alcohol intake and 8-year weight gain in women: a prospective study. Obes Res 2004, 12(9):1386-1396.

19. Proper K, Cerin E, Brown W, Owen N: Sitting time and socio-economic differences in overweight and obesity. Int J Obes 2007, 31(1):169-176.

20. Ball $K$, Crawford D, Ireland P, Hodge A: Patterns and demographic predictors of 5year weight change in a multiethnic cohort of men and women in Australia. Public Health Nutr 2003, 6(3):269-280.

21. Guelinckx I, Devlieger R, Beckers K, Vansant G: Maternal obesity: pregnancy complications, gestational weight gain and nutrition. Obes Rev 2008, 9(2):140-150.

22. Olson C, Strawderman M, Dennison B: Maternal weight gain during pregnancy and child weight at age 3 years. Matern Child Health J 2009, 13(6):839-846.

23. Ball K, Mishra G: Whose socioeconomic status influences a woman's obesity risk: her mother's, her father's or her own? Int J Epidemiol 2006, 35(1):131-138

24. Greenlund K, Liu K, Dyer A, Kiefe C, Burke G, Yunis C: Body mass index in young adults: Associations with parental body size and education in the CARDIA study. Am J Public Health 1996, 86(4):480-485.

25. Lee C, Dobson A, Brown W, Bryson L, Byles J, Warner-Smoth P, Young A: Cohort profile: The Australian Longitudinal Study on Women's Health. Int J Epidemiol 2005, 34(5):987-991.

26. Brown W, Bryson L, Byles J, Dobson A, Lee C, Mishra G, Schofield M: Women's Health Australia: recruitment for a national longitudinal cohort study. Women Health 1998, 28(1):23-40. 
27. Spratt M, Carpenter J, Sterne J, Carlin J, Heron J, Henderson J, Tilling K: Strategies for multiple imputation in longitudinal studies. Am J Epidemiol 2010, 172(4):478-487.

28. NHMRC (National Health and Medical Research Council): Australian Alcohol Guidelines: Health risks and benefits. Canberra: Australian Government Publishing Service; 2001. http://www.nhmrc.gov.au/_files_nhmrc/publications/ attachments/ds9.pdf.

29. Brown W, Burton N, Marshall A, Miller Y: Reliability and validity of a modified self-administered version of the Active Australia physical activity survey in a sample of mid-age women. Aust NZ J Public Health 2008, 32(6):535-541.

30. Berwick D, Murphy J, Goldman P, Ware J, Barksy A, Weinstein M: Performance of a five-item mental health screening test. Med Care 1991, 29(2):169-176.

31. World Health Organisation (WHO): WHO BMI Classification. In Global Database on Body Mass Index. 2013. http://apps.who.int/bmi/index.jsp? introPage=intro_3.html.

32. Singer J: Using SAS PROC MIXED to fit multilevel models, hierarchical models, and individual growth models. J Educ Behav Stat 1998, 24(4):323-355.

33. Greenland S: Modeling and variable selection in epidemiologic analysis. Am J Public Health 1989, 79(3):340-349.

34. Loman T, Lallukka T, Laaksonen M, Rahkonen O, Lahelma E: Multiple socioeconomic determinants of weight gain: the Helsinki Health Study. BMC Public Health 2013, 13(1):259.

35. Botoseneanu A, Liang J: Social stratification of body weight trajectory in middle-age and older Americans: results from a 14-year longitudinal study. J Aging Health 2011, 23(3):454-480.

36. Mackenbach J: New trends in health inequalities research: now it's personal. Lancet 2010, 376(9744):854-855.

37. Sullivan S, Cloniger C, Przybeck T, Klein S: Personality characteristics in obesity and relationship with successful weight loss. Int J Obes 2007, 31(4):669-674.

38. Spencer E, Appleby P, Davey G, Key T: Validity of self-reported height and weight in 4808 EPIC-Oxford participants. Public Health Nutr 2002 5(4):561-565.

39. Koupil I, Toivanen P: Social and early life determinants of overweight and obesity in 18 year old Swedish men. Int J Obes 2008, 32(1):72-81.

40. Abu-Rmeileh N, Hart C, McConnachie A, Upton M, Lean M, Watt G: Contribution of midparental BMI and other determinants of obesity in adult offspring. Obesity 2008, 16(6):1388-1393.

doi:10.1186/1471-2458-14-1219

Cite this article as: Holowko et al.: Educational mobility and weight gain over 13 years in a longitudinal study of young women. BMC Public Health 2014 14:1219.

\section{Submit your next manuscript to BioMed Central and take full advantage of:}

- Convenient online submission

- Thorough peer review

- No space constraints or color figure charges

- Immediate publication on acceptance

- Inclusion in PubMed, CAS, Scopus and Google Scholar

- Research which is freely available for redistribution 